\title{
Mel de abelhas sem ferrão: proposta de regulamentação
}

Stingless bee honey: technical regulation proposal

\author{
Ricardo Costa Rodrigues de Camargo', Karen Linelle de Oliveira ${ }^{2}$, Maria Isabel Berto ${ }^{2 \star}$ \\ ${ }^{1}$ Embrapa Meio-Ambiente, Núcleo de Agroecologia, Jaguariúna/SP - Brasil \\ IInstituto de Tecnologia de Alimentos (ITAL), Grupo de Engenharia de Processos (GEPC), Campinas/SP - Brasil
}

\section{*Corresponding Author}

Maria Isabel Berto, Instituto de Tecnologia de Alimentos (ITAL), Grupo de Engenharia de Processos (GEPC), Caixa Postal: 139, CEP: 13070-178, Campinas/SP - Brasil, e-mail: miberto@ital.sp.gov.br

Cite as: Stingless bee honey: technical regulation proposal. Braz. J. Food Technol., v. 20, e2016157, 2017.

Received: Oct. 31, 2016; Accepted: Nov. 11, 2016

\section{Resumo}

Os méis das abelhas sem ferrão são produtos únicos da biodiversidade brasileira, presentes e valorizados pela cultura popular desde os povos originais das Américas. Por ser mais ácido e apresentar maior teor de umidade, seu sabor é peculiar e sua viscosidade é menor quando comparada ao mel proveniente da espécie exótica Apis mellifera. Devido a essas diferenças, esse produto necessita do estabelecimento de parâmetros físico-químicos específicos que sejam referência tanto para controle de qualidade como para sua comercialização. Com base em pesquisas realizadas pela Embrapa, pelo Instituto de Tecnologia de Alimentos de Campinas e pelo levantamento bibliográfico de diversos estudos científicos realizados por outros institutos de ensino e pesquisa, esta comunicação tem como objetivo esclarecer as peculiaridades deste produto e apresentar uma proposta de Regulamento Técnico de Identidade e Padrão para o Mel das Abelhas Sem Ferrão, visando sua comercialização no Estado de São Paulo, contribuindo assim para a disponibilidade de um produto seguro e de qualidade para o consumidor final.

Palavras-chave: Mel de abelhas sem ferrão; Abelhas nativas; Regulamentação; Meliponicultura; Melipona.

\section{Summary}

Stingless bee honeys are unique products from the Brazilian biodiversity, present and appreciated by popular culture since the original peoples of the Americas. The greater acidity and moisture content of this honey make its flavour unusual and its viscosity lower when compared with the honey from the exotic species Apis mellifera. Due to these differences, this product requires the establishment of specific physical and chemical parameters to serve as a reference for both quality control and marketing purposes. Based on research carried out by Embrapa and the Institute of Food Technology in Campinas, Brazil, and also on a literature review of several scientific studies carried out by other research and educational institutes, this communication aims to clarify the peculiarities of this product and present a proposal for a Technical Regulation for stingless bee honeys aimed at its marketing in the state of São Paulo, Brazil, thus contributing to the availability of a safe product of good quality for the final consumer.

Keywords: Stingless bee honey; Stingless bee; Regulation; Meliponiculture; Meliponas.

\section{Introdução}

As abelhas da subfamília Meliponinae (Hymenoptera, Apidae) são conhecidas como Abelhas sem Ferrão (ASF), por possuírem ferrão atrofiado e, portanto, incapazes de ferroar. Atualmente, estão agrupadas taxonomicamente em uma tribo apenas, "Meliponini", com 32 gêneros, sendo o gênero Melipona o único que apresenta um processo diferenciado dos demais para a produção de rainhas. Esse gênero engloba inúmeras espécies produtoras de mel que vêm sendo criadas há centenas de anos pelos povos tradicionais das Américas.

A imensa maioria das abelhas alimenta-se de produtos obtidos das flores, coletando seu néctar e transformando-o 
em mel por desidratação e ação enzimática (CAMPOS; PERUQUETTI, 1999).

No Brasil, os povos indígenas já apreciavam este tipo de mel e sazonalmente faziam sua coleta nos locais onde as colônias dessas abelhas eram identificadas na floresta. Esse produto também é valorizado na medicina popular, sendo-lhe atribuída uma série de propriedades terapêuticas, usado puro ou em conjunto com plantas medicinais na formulação de "preparados" (garrafadas) medicinais.

Como a produção desse mel muitas vezes é regionalizada e o volume disponível é menor, seu valor no mercado é muitas vezes maior do que o do mel produzido pelas abelhas "africanizadas", criadas pelos apicultores brasileiros e presentes em todo o território nacional.

A diversidade de flora e biomas do Brasil e a grande variedade de espécies de abelhas sem ferrão existente conferem a esse mel um enorme potencial para produção e valorização dessa variedade de méis produzidos por essas abelhas. Além da importância econômica para os produtores, esse produto possui características sensoriais diferenciadas dos méis tradicionalmente consumidos no Brasil, tornando-o um produto com alto valor agregado (HOLANDA et al., 2012).

\section{Caracterização do problema}

Uma das principais características composição físico-química do mel de ASF, que o difere dos méis das abelhas africanizadas, é o seu maior teor de umidade, que consequentemente eleva sua atividade de água, tornando-o mais susceptível ao crescimento microbiano, principalmente pela presença de leveduras em sua composição original. Esse teor de umidade resulta em um mel menos viscoso e em uma cristalização mais lenta quando comparada à do mel de Apis mellifera (SILVA, 2012; CAMPOS; PERUQUETTI, 1999).

A atividade de água $(\mathrm{Aa})$ juntamente com o pH, relacionado ao grau de acidez, definem as condições para o crescimento microbiano no produto. O mel de Apis é um produto microbiologicamente estável, pois possui valores de atividade de água inferiores a 0,6 (BLACK; BARACH, 2015). Estudos desenvolvidos por Dias et al. (2014) avaliaram o pH e atividade de água de mais de 30 amostras de méis de ASF, das tribos Meliponini e Trigonini, e encontraram faixas de Aa de 0,67 a 0,75 e pH de 3,49 a 4,65. Apesar de esta faixa de atividade de água ser limitante para desenvolvimento de micro-organismos patogênicos, fungos e leveduras osmofílicas podem se desenvolver.

Métodos de manejo, colheita e beneficiamento do mel de ASF que não obedecem às Boas Práticas de Fabricação, associados à umidade elevada (21\% a 45\%) e à presença de micro-organismos, podem acarretar problemas de conservação do produto, reduzindo sua vida de prateleira, podendo até mesmo torná-lo impróprio para o consumo humano (ALVES et al., 2011).

Algumas técnicas de conservação são indicadas e vêm sendo utilizadas por meliponicultores. Entretanto, os métodos de conservação aplicados muitas vezes foram concebidos empiricamente e o produto final não passa por uma avaliação adequada antes de ser comercializado. Dentre os métodos aplicados destacam-se: refrigeração logo após a colheita; desidratação, ocasionando a redução da umidade; fermentação do mel colhido pela sua própria microbiota, provocando um aumento da acidez; e processo térmico de pasteurização, visando à redução da carga microbiana vegetativa.

Devido às diferenças na composição físico-química, os valores de referência indicados para o controle da qualidade e comercialização de mel, nas legislações nacionais (BRASIL, 2000) e internacionais (FAO, 2001) vigentes, não são aplicáveis para os méis das ASF. O desenvolvimento e a aprovação de uma regulamentação para os méis de ASF, estabelecendo os requisitos de identidade e padrão são importantes para a garantia de segurança de consumo e para que os órgãos fiscalizadores tenham base referencial para sua inspeção, permitindo a comercialização oficial.

Neste contexto, com base em pesquisas realizadas pela Embrapa, pelo Instituto de Tecnologia de Alimentos de Campinas - SP e também pelo levantamento bibliográfico de estudos científicos realizados por diversos institutos de ensino e pesquisa do país, é apresentada a proposta de um Regulamento Técnico de Identidade e Padrão para - Mel das ASF para o seu controle de qualidade e devida comercialização no Estado de São Paulo.

\section{Proposta de regulamento técnico de identidade e padrão de mel de abelha sem ferrão Meliponinae}

\subsection{Alcance}

\subsubsection{Objetivo}

Estabelecer a identidade e os requisitos mínimos de controle da qualidade a que o Mel de Abelha sem Ferrão - ASF, destinado ao consumo humano direto, deve atender.

Este Regulamento não se aplica para mel de abelha sem ferrão industrial que possa ser utilizado como ingrediente em outros alimentos.

\subsection{2 Âmbito de aplicação}

O presente Regulamento Técnico se aplicará em todo o Estado de São Paulo. 


\subsection{Classificação}

\subsubsection{Por sua origem}

3.2.1.1 Mel floral: é o mel obtido dos néctares das flores

a) Mel unifloral ou monofloral:

Produto predominantemente originário de flores de uma mesma família, gênero ou espécie e que possua características sensoriais, físico-químicas e microscópicas próprias.

b) Mel multifloral ou polifloral:

Produto obtido a partir de diferentes origens florais.

\subsubsection{Mel extrafloral}

Produto obtido a partir de nectários extraflorais.

\subsubsection{Melato}

Produto obtido a partir da secreção de insetos sugadores de seiva ou de outras partes vivas das plantas.

\subsubsection{Pelo método de extração}

\subsubsection{Por sucção}

Método em que o mel é retirado dos potes por equipamentos que promovam uma diferença de pressão.

\subsubsection{Por escoamento}

Método em que o mel escorre dos potes abertos pela inversão da alça superior ou melgueira.

\subsubsection{Pela apresentação}

\subsubsection{Mel líquido}

Mel em estado líquido original.

\subsubsection{Mel cristalizado}

Mel em estado sólido ou parcialmente sólido, pela formação de cristais, a partir da cristalização das moléculas de açúcares, principalmente glicose e frutose.

\subsubsection{Mel cremoso}

Mistura de mel líquido com mel cristalizado em diferentes proporções.

\subsubsection{Mel em pote}

Mel acondicionado em potes naturais ou artificiais.

\subsubsection{Pelo processamento}

\subsubsection{Mel in natura}

Mel extraído dos potes e mantido sob refrigeração logo após a sua coleta até o momento do consumo, não submetido a qualquer outro processamento.

\subsubsection{Mel desidratado}

Mel que após a extração é submetido ao processo de desidratação, no qual ocorre redução do teor de umidade e da atividade de água, visando ao aumento da sua vida de prateleira em temperatura ambiente.

\subsubsection{Mel pasteurizado}

Mel que após a extração passa por processo térmico de pasteurização para redução e/ou inibição do desenvolvimento microbiológico e/ou da atividade enzimática no produto, sendo posteriormente mantido à temperatura ambiente ou sob refrigeração.

\subsubsection{Mel maturado}

Mel que após a extração passa pelo processo de maturação em temperatura ambiente, caracterizado por sua fermentação natural, a partir do desenvolvimento das leveduras osmofílicas naturalmente presentes.

\subsection{Composição e requisitos}

\subsubsection{Composição}

O mel de ASF é uma solução concentrada de açúcares com predominância de glicose e frutose. Contém ainda uma mistura complexa de outros carboidratos, enzimas, aminoácidos, ácidos orgânicos, minerais, substâncias aromáticas, pigmentos e grãos de pólen.

Comparando-o com o mel de Apis, apresenta maior concentração de água, podendo conter cerume procedente do seu processo de extração.

O produto definido nesta Norma não pode ser adicionado de açúcares e/ou outras substâncias que alterem a sua composição original.

\subsubsection{Requisitos}

\subsubsection{Características sensoriais}

\subsection{Cor}

Variável de quase incolor a pardo-escuro, de acordo com a sua origem, segundo definição no item em 3.2.1 desta Norma.

\subsection{Sabor e aroma}

Deve ter sabor e aroma característicos de acordo com a sua origem, segundo definição no item 3.2.1 desta Norma.

\subsection{Consistência}

Variável de acordo com o estado físico em que o mel se apresenta, segundo definição no item 3.2.3 desta Norma. 
Mel de abelhas sem ferrão: proposta de regulamentação

Camargo, R. C. R. et al.

\subsubsection{Características físico-químicas}

Na Tabela 1, estão descritos os parâmetros a serem analisados no mel de abelhas nativas sem ferrão, relacionados às características físico-químicas de maturidade, pureza e deterioração, seus respectivos limites e referências das metodologias analíticas.

\subsection{Aditivos}

É expressamente proibida a utilização de qualquer tipo de aditivos.

\subsection{Acondicionamento}

O mel, a granel ou fracionado, deve ser acondicionado em embalagem própria para alimento, que preserve as suas características e confira proteção contra contaminação.

\subsection{Armazenamento}

O mel deve ser armazenado em local e sob condições que preservem suas características e evite contaminações.

O mel in natura definido no item 3.2.4.1 desta Norma, deve ser mantido em temperaturas de refrigeração de 4 a $8{ }^{\circ} \mathrm{C}$ durante armazenamento.

O mel pasteurizado definido no item 3.2.4.3 pode ser mantido em temperaturas de refrigeração de 4 a $8^{\circ} \mathrm{C}$ e em temperatura ambiente.

O mel desidratado e/ou o mel maturado, definidos respectivamente nos itens 3.2.4.2 e 3.2.4.4, podem ser mantidos e comercializados em temperatura ambiente, desde que as características físico-químicas sejam preservadas.
O acondicionamento do mel in natura, pasteurizado, desidratado e/ou maturado de abelha sem ferrão deve ser realizado em embalagem a granel ou fracionada, apta para alimento, devidamente rotulada e adequada para as condições previstas de armazenamento, conferindo proteção apropriada contra a contaminação.

\subsection{Contaminantes}

Os contaminantes orgânicos e inorgânicos não devem estar presentes em quantidades superiores aos limites estabelecidos na legislação vigente (BRASIL, 2013).

\subsubsection{Critérios microbiológicos}

O produto deverá estar de acordo com os requisitos apresentados na Tabela 2.

\subsection{Higiene}

\subsection{Considerações gerais}

As práticas de higiene para elaboração do produto devem estar de acordo com legislação vigente (BRASIL, 1996, 2001).

\subsubsection{Critérios macroscópicos e microscópicos}

O mel deve estar isento de substâncias estranhas, de qualquer natureza, tais como insetos e suas partes, larvas, grãos de areia e outros, de acordo com legislação vigente para matérias estranhas macroscópicas e microscópicas em alimentos e bebidas (BRASIL, 2014).

\subsection{Pesos e Medidas}

Para o mel de ASF, deve ser utilizada a medida de volume, sendo expressa em litro ou mililitro.

Tabela 1. Parâmetros relacionados às características físico-químicas de maturidade, pureza e deterioração do mel de ASF, respectivos limites e referências metodológicas.

\begin{tabular}{|c|c|c|c|}
\hline $\begin{array}{l}\text { Características } \\
\text { físico-químicas }\end{array}$ & Parâmetros & Limites & Referências \\
\hline \multirow{5}{*}{ Maturidade } & Açúcares redutores (calculados como açúcar invertido) & Mínimo 60g/100g & IHC (2002) \\
\hline & Sacarose aparente & Máximo 6g/100g & IHC (2002) \\
\hline & Umidade & & \\
\hline & a) Mel desumidificado & Máximo 20g/100g & AOAC (2010a) \\
\hline & b) Mel in natura, pasteurizado ou maturado & Máximo 40g/100g & \\
\hline \multirow{3}{*}{ Pureza } & Sólidos insolúveis em água & Máximo 0,1g/100g & FSA (1992a) \\
\hline & Minerais (cinzas) & Máximo 0,6g/100g & IHC (2002) \\
\hline & Pólen & $\begin{array}{l}\text { Presença de grãos de } \\
\text { pólen }\end{array}$ & Louveaux et al. (1978) \\
\hline \multirow{5}{*}{ Deterioração } & $\mathrm{pH}$ & 2,9 a 4,5 & IHC (2002) \\
\hline & Acidez livre & Máximo 50 mEq/kg & FSA (1992b) \\
\hline & Atividade de água & 0,52 a 0,80 & AOAC (2010b) \\
\hline & Hidroximetilfurfural & Máximo de 20 mg/kg & AOAC (2010c) \\
\hline & O mel não deve ter indícios de fermentação & & \\
\hline
\end{tabular}


Mel de abelhas sem ferrão: proposta de regulamentação

Camargo, R. C. R. et al.

Tabela 2. Critérios microbiológicos para mel de abelhas sem ferrão.

\begin{tabular}{|c|c|c|c|c|c|c|}
\hline \multirow[t]{2}{*}{ Micro-organismos } & \multirow{2}{*}{$\begin{array}{c}\text { Tolerância para } \\
\text { amostra indicativa }\end{array}$} & \multicolumn{4}{|c|}{ Tolerância para amostra representativa } & \multirow[t]{2}{*}{ Método de análise } \\
\hline & & $\mathbf{n}$ & c & $\mathbf{m}$ & M & \\
\hline $\begin{array}{l}\text { Coliformes a } 45^{\circ} \mathrm{C} \\
(\mathrm{NMP} / \mathrm{g} \text { ou } \mathrm{mL})\end{array}$ & $10^{2}$ & 5 & 2 & 10 & $10^{2}$ & Downes e Ito (2001) \\
\hline $\begin{array}{l}\text { Bolores e leveduras } \\
\text { (UFC/g ou } \mathrm{mL} \text { ) }\end{array}$ & $10^{4}$ & 5 & 2 & $10^{3}$ & 104 & Downes e Ito (2001) \\
\hline Salmonella em $25 \mathrm{~g}$ & Ausência & 5 & 0 & Ausência & --- & FDA (1995) \\
\hline
\end{tabular}

$\mathrm{n}$ : número de unidades a serem colhidas aleatoriamente em um mesmo lote e analisadas individualmente; M: limite que, em plano de duas classes, separa o produto aceitável do inaceitável (valores acima de M são inaceitáveis); m: é limite que, em um plano de três classes, separa o lote aceitável do produto ou lote com qualidade intermediária aceitável; c: número máximo aceitável de unidades de amostras com contagens entre os limites de $\mathrm{m}$ e $\mathrm{M}$.

\subsection{Rotulagem}

A rotulagem deve estar de acordo com a legislação vigente para rotulagem de alimentos embalados (BRASIL, 1993).

O produto se denominará Mel de ASF ou Melato de ASF, de acordo com o item 3.2.1 desta Norma.

Deve ser informado o tipo de processamento e o nome científico da espécie de abelha sem ferrão, acrescido ou não do nome popular na região.

A indicação da florada predominante na rotulagem deve ser comprovada por metodologia analítica específica (melissopalinologia).

\section{Referências}

ALVES, T. T. L.; MENESES, A. R. V.; SILVA, J. N.; PARENTE, G. D. L.; HOLANDA NETO, J. P. Caracterização físico-química e avaliação microbiológica de méis de abelhas nativas do nordeste brasileiro. Revista Verde, Mossoró, v. 6, n. 3, p. 91-97, 2011.

ASSOCIATION OF OFFICIAL ANALYTICAL CHEMISTS - AOAC. 969.38: moisture in honey. Washington: AOAC, 2010a.

ASSOCIATION OF OFFICIAL ANALYTICAL CHEMISTS - AOAC. 978.18: water activity of canned vegetables. Washington: AOAC, 2010b.

ASSOCIATION OF OFFICIAL ANALYTICAL CHEMISTS - AOAC. 980.23: hydroxymethylfurfural in honey. Washington: AOAC, 2010c.

BLACK, D. G.; BARACH, J. T. Canned foods: principles of thermal process control acidification and container closure evaluation. 8. ed. Washington: Grocery Manufacture Association (GMA), 2015. $190 \mathrm{p}$.

BRASIL. Ministério da Agricultura e do Abastecimento. Portaria $n^{\circ}$ 368, de 04 de setembro de 1997. Aprova o Regulamento técnico sobre as condições higiênico-sanitárias e de boas práticas de elaboração para estabelecimentos elaboradores/ industrializadores de alimentos. Diário Oficial [da] República Federativa do Brasil, Brasília, DF, 4 set. 1997. Seção 1. Disponível em: <http://www.agricultura.gov.br>. Acesso em: 21 set. 2016.

BRASIL. Ministério da Agricultura e do Abastecimento. Instrução normativa $n^{\circ} 11$, de 20 de outubro de 2000 . Aprova o regulamento técnico de identidade e qualidade do mel. Diário Oficial [da] República Federativa do Brasil, Brasília, DF, 23 out. 2000.

BRASIL. Ministério da Saúde. Agência Nacional de Vigilância Sanitária - ANVISA. Resolução RDC $n^{\circ} 12$, de 02 de janeiro 2001. Regulamento técnico sobre padrões microbiológicos em alimentos. Diário Oficial [da] República Federativa do Brasil, Brasília, DF, 10 jan. 2001. Seção 1. Disponível em: <http://www. anvisa.gov.br>. Acesso em: 27 set. 2016.

BRASIL. Ministério da Saúde. Agência Nacional de Vigilância Sanitária - ANVISA. Resolução n 360, de 23 de dezembro de 2003. Regulamento técnico sobre rotulagem nutricional de alimentos embalados. Diário Oficial [da] República Federativa do Brasil, Brasília, DF, 26 dez. 2003. Seção 1, n. 251, p. 33. Disponível em: <http://www.anvisa.gov.br>. Acesso em: 21 set. 2016.

BRASIL. Ministério da Saúde. Agência Nacional de Vigilância Sanitária - ANVISA. Resolução RDC n 42, de 29 de agosto de 2013. Regulamento técnico MERCOSUL sobre limites máximos de contaminantes inorgânicos em alimentos. Diário Oficial [da] República Federativa do Brasil, Brasília, DF, 29 ago. 2013. Seção 1, p. 33. Disponível em: <http://www.anvisa.gov.br>. Acesso em: 16 set. 2016.

BRASIL. Ministério da Saúde. Agência Nacional de Vigilância Sanitária - ANVISA. Resolução RDC n 14, de 28 de março de 2014. Regulamento técnico sobre matérias estranhas macroscópicas e microscópicas em alimentos e bebidas. Diário Oficial [da] República Federativa do Brasil, Brasília, DF, 28 mar. 2014. Seção 1, p. 58 . Disponível em: <http://www.anvisa.gov.br>. Acesso em: 28 set. 2016.

CAMPOS, L. A. O.; PERUQUETTI, R. C. Biologia e criação de abelhas sem ferrão. Viçosa: Conselho de Extensão, Departamento de Biologia Geral, Universidade Federal de Viçosa, 1999. 38 p. (Informe Técnico, 82). Disponível em: <http://ftp.ufv.br/dbg/ apiario/meliponini.pdf>. Acesso em: 23 set. 2016.

DIAS, M. P. S.; CAMARGO, R. C. R.; OLIVEIRA, K. L.; BERTELI, M. N.; BERTO, M. I. Levantamento de tecnologias de conservação de mel de abelhas nativas em função de suas propriedades físico-químicas. In: CONGRESSO INTERINSTITUCIONAL DE INICIAÇÃO CIENTÍFICA - CIIC 2014, 8., 2014, Campinas. Anais... Campinas: ITAL, 2014. 
Mel de abelhas sem ferrão: proposta de regulamentação

Camargo, R. C. R. et al.

DOWNES, F. P.; ITO, K. Compendium of methods for the microbiological examination of foods. 4. ed. Washington: APHA, 2001. 676 p.

FOOD AND AGRICULTURE ORGANIZATION OF THE UNITED NATIONS - FAO. Codex Alimentarius Commission. Codex Stan 12-1981: Codex Standard for honey. |Roma: FAO, 2001. 8 p.

FOOD AND DRUG ADMINISTRATION - FDA. Bacteriological analytical manual (BAM). 8. ed. USA: FDA, 1995.

FOOD STANDARDS AGENCY - FSA. Water-insoluble solids in honey. Journal of the Association of Public Analysts, London, v. 22, n. 28 , p. $189-193,1992 a$.

FOOD STANDARDS AGENCY - FSA. Acidity in honey. Journal of the Association of Public Analysts, London, v. 19, n. 28, p. 171-175, 1992b.
HOLANDA, C. A.; OLIVEIRA, A. R.; COSTA, M. C. P.; RIBEIRO, M. N. S.; SOUZA, J. L.; ARAÚJO, M. J. A. M. Qualidade dos méis produzidos por Melipona fasciculata smith da região do cerrado maranhense. Química Nova, São Paulo, v. 35, n. 1, p. 55-58, 2012. http://dx.doi.org/10.1590/S0100-40422012000100011.

INTERNATIONAL HONEY COMMISSION - IHC. Harmonised methods of the International Honey Commission. Switzerland: IHC, 2002. 62 p.

LOUVEAUX, J.; MAURIZIO, A.; VORWOHL, G. Methods of melissopalynology. Bee World, Maryland, v. 59, n. 4, p. 139-157, 1978. http://dx.doi.org/10.1080/0005772X.1978.11097714.

SILVA, W. P. Abelhas sem ferrão: muito mais do que uma importância econômica. Natureza on line, Santa Teresa, v. 10, n. 3, p. 146-152, 2012. Disponível em: <www.naturezaonline. com.br>. Acesso em: 3 out. 2016. 


\section{Errata}

No artigo Mel de abelhas sem ferrão: proposta de regulamentação, com número de DOI: http://dx.doi.org/10.1590/19816723.15716, publicado no periódico Brazilian Journal of Food Technology, vol. 20, e2016157, 6 p., na página 4:

Onde se lia:

Tabela 1. Parâmetros relacionados às características físico-químicas de maturidade, pureza e deterioração do mel de ASF, respectivos limites e referências metodológicas.

\begin{tabular}{|c|c|c|c|}
\hline $\begin{array}{l}\text { Características } \\
\text { físico-químicas }\end{array}$ & Parâmetros & Limites & Referências \\
\hline \multirow{5}{*}{ Maturidade } & Açúcares redutores (calculados como açúcar invertido) & Mínimo 60g/100g & IHC (2002) \\
\hline & Sacarose aparente & Máximo 6g/100g & IHC (2002) \\
\hline & Umidade & & \\
\hline & a) Mel desumidificado & Máximo 20g/100g & AOAC (2010a) \\
\hline & b) Mel in natura, pasteurizado ou maturado & Máximo 40g/100g & \\
\hline \multirow{3}{*}{ Pureza } & Sólidos insolúveis em água & Máximo 0,1g/100g & FSA (1992a) \\
\hline & Minerais (cinzas) & Máximo 0,6g/100g & IHC (2002) \\
\hline & Pólen & Presença de grãos de pólen & Louveaux et al. (1978) \\
\hline \multirow{5}{*}{ Deterioração } & $\mathrm{pH}$ & 2,9 a 4,5 & IHC (2002) \\
\hline & Acidez livre & Máximo $50 \mathrm{mEq} / \mathrm{kg}$ & FSA (1992b) \\
\hline & Atividade de água & 0,52 a 0,80 & AOAC (2010b) \\
\hline & Hidroximetilfurfural & Máximo de 20 mg/kg & AOAC (2010c) \\
\hline & O mel não deve ter indícios de fermentação & & \\
\hline
\end{tabular}

Leia-se:

Tabela 1. Parâmetros relacionados às características físico-químicas de maturidade, pureza e deterioração do mel de ASF, respectivos limites e referências metodológicas.

\begin{tabular}{|c|c|c|c|}
\hline $\begin{array}{l}\text { Características } \\
\text { físico-químicas }\end{array}$ & Parâmetros & Limites & Referências \\
\hline \multirow{5}{*}{ Maturidade } & Açúcares redutores (calculados como açúcar invertido) & Mínimo 60g/100g & IHC (2002) \\
\hline & Sacarose aparente & Máximo 6g/100g & IHC (2002) \\
\hline & Umidade & & \\
\hline & a) Mel desumidificado & Máximo 20g/100g & AOAC (2010a) \\
\hline & b) Mel in natura, pasteurizado ou maturado & Máximo 40g/100g & \\
\hline \multirow{3}{*}{ Pureza } & Sólidos insolúveis em água & Máximo 0,1g/100g & FSA (1992a) \\
\hline & Minerais (cinzas) & Máximo 0,6g/100g & $\mathrm{IHC}(2002)$ \\
\hline & Pólen & Presença de grãos de pólen & Louveaux et al. (1978) \\
\hline \multirow{5}{*}{ Deterioração } & $\mathrm{pH}$ & 2,9 a 4,5 & IHC (2002) \\
\hline & Acidez livre & Máximo $50 \mathrm{mEq} / \mathrm{kg}$ & FSA (1992b) \\
\hline & Atividade de água & 0,52 a 0,80 & AOAC (2010b) \\
\hline & Hidroximetilfurfural & Máximo de 20 mg/kg & AOAC (2010c) \\
\hline & O mel não deve apresentar indícios de fermentação, con & exceção do mel maturado & \\
\hline
\end{tabular}

